\title{
Characteristics of Gas Emissions in Landfill Site in Recent Years
}

\author{
Park Chan Jin
}

\begin{abstract}
The characteristics of gas emissions in landfill sites in recent years were investigated in Incheon area. The mechanism of landfill gas generation was considered to explain the tendency of gas components, and especially methane and carbon dioxide gas were analyzed through several methods of greenhouse gas calculation. From the study the optimal management methods of landfill site were considered and control of odorous components investigated.
\end{abstract}

Index Terms - Landfill, gas emission, odorous component.

\section{INTRODUCTION}

The general way to treat waste materials is to bury in the earth or incinerate with thermal energy. Both methods have benefits and dis-advantages with environmental point of view. But, the worst factor of incineration would be the dioxin related toxicology. And the landfill gas related with the global warming would be the urgent problem which should be solved for the prevention of greenhouse effect.

As the amount of burried materials is increased, LFG is generally increased until getting more and more serious global warming, various solutions are made to make less serious those problems which are related to world climate changes.

Every country is trying to estimate \& reduce greenhouse gas emissions from all possible sources to keep promise in Kyoto protocol, therefore the analysis of landfill gas components and accurate estimation of greenhouse gas from landfill is very important in these days. The wastses of human living are simply burried to landfill site in Korea, and then continuous guarantee of landfill regions are indispensible. In Incheon metropolitan city, there is a enormous utility for landfill and our main concerns for study is this landfill region.

Nowadays the main components of landfill gas which are mainly methane and carbon dioxide gas are monitored and the greenhouse gas is not emitteddirectlyinto atmosphere. This gas is collected with blower system, and is carried to the recycling system which is composed of electric generation and refrigeration and incineratin plants.

Especially the electric generation with methane gas can be classified as the Clean Development Mechanism which is related with the carbon emission reduction defined in Kyoto climate conference. The tendency of landfill gas components was investigated with recent years.

Manscprit received May 29, 2014; revised August 2, 2014.

Park Chan Jin is with School of Urban \& Environmental Eng., Incheon National University, Republic of Korea (e-mail: cjpark@incheon.ac.kr).

\section{EXPERIMENTAL}

In general, major components of landfill gas are dependent on factors with gas generation and degradableorganic componentsdecomposes with landfill process. This procedure is proceeded with complex steps with physical, chemical and biological which is main course of methane generation. The general mechanism of gas generation is classified into four steps which is shown in Fig. 1 [1].

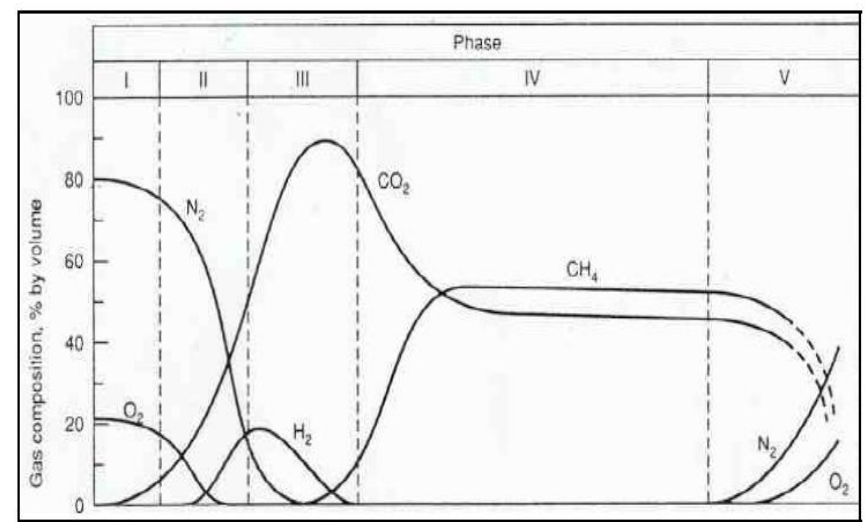

Fig. 1. Steps of landfill gas generation

The main gas components in the landfill regions are ammonia, carbon dioxide, carbon monoxide, hydrogen, nitrogen and oxygen. And the period of gas generation is generally 7 to 18 years, the major odor components are hydrogen sulfides, ammonia, acetic aced, mercaptans and amines.

The four major steps depicted in Fig. 1 are described as follows [2]. The first step is that organic components which are bio-degradable is decomposed to carbon dioixdes consuming oxygens in landfill regions. The second step is initial acid formation stage that acid formation microbes make fatty acids, hydrogen and carbon dioxides under anaerobic condition. And the third stage is that the organic acids increase rapidly with the action of microbes and the decrease of carbon dioxides and hydrogen begin gradually.

The fourth step is the conversion of acetic acid and hydrogen into methane and carbon dioxide, in this stage the conversion rate becomes larger than other stage. And the final step is maturing steps which methane and carbon dioxide diminish and nitrogen, oxygen increase [2].

\section{RESULTS AND DISCUSSION}

Major components of landfill gas are methane, carbon dioxide gas, ammonia, nitrous oxides \&sulfur oxides as described earlier. The degradation of wastes in landfill sites are primarily due to physical, chemical and biological 
processes, \& major greenhouse gases are methane gas [3]. The composition oflandfill gasin recent years is shown inTable I [4] Our main concerns are greenhouse landfill gas.
Main method of greenhouse gas emission is that of IPCC (Intergovernmental Panel of Climate Change) 2006 manuals as follows [5].

\begin{tabular}{|l|l|l|l|l|l|l|l|l|l|l|l|l|}
\hline Years & 2003 & 2004 & 2005 & 2006 & 2007 & 2008 & 2009 & 2010 & 2011 & 2012 & 2013 \\
\hline $\mathrm{CH}_{4}(\%)$ & 48.7 & 45.8 & 46.0 & 46.1 & 47.4 & 47.7 & 44.3 & 44.9 & 43.9 & 43.6 & 43.3 \\
\hline $\mathrm{CO}_{2}(\%)$ & 33.9 & 35.5 & 42.7 & 47.1 & 46.7 & 43.2 & 32.9 & 32.9 & 35.0 & 33.8 & 34.7 \\
\hline $\mathrm{NH}_{3}(\mathrm{ppm})$ & 1.21 & 1.17 & 2.05 & 2.99 & 12.1 & 12.6 & 14.5 & 8.4 & 14.9 & 53.8 & 131.0 \\
\hline $\mathrm{H}_{2} \mathrm{~S}(\mathrm{ppm})$ & 49.9 & 49.4 & 57.5 & 125 & 162 & 103 & 142 & 78.5 & 675 & 1,329 & 1,991 \\
\hline $\mathrm{NO}_{2}(\mathrm{ppm})$ & 0.44 & 0.46 & 0.60 & 0.63 & 0.33 & 0.8 & 0.56 & 0.49 & - & 43.0 & 3.50 \\
\hline $\mathrm{SO}_{2}(\mathrm{ppm})$ & 0.39 & 0.39 & 0.43 & 0.55 & 0.81 & 0.98 & 1.35 & 0.57 & 3,920 & 2,125 & 729 \\
\hline
\end{tabular}

$$
\begin{aligned}
& \mathrm{DDOCma}_{T}=\mathrm{DDOCmd}_{T}+\left(\mathrm{DDOCma}_{T-1} \times e^{-k}\right) \\
& \text { DDOCmdecomp } p_{T}=\text { DDOCma } a_{T-1} \times\left(1-e^{-k}\right)
\end{aligned}
$$

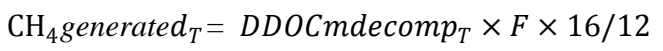

$$
\begin{aligned}
& \mathrm{CH}_{4} \text { emitted }_{T}=\left(\Sigma C \mathrm{H}_{4} \text { generated }_{x, T}-R_{T}\right) \times\left(1-O X_{T}\right)
\end{aligned}
$$

where

$D D O C m=$ Amount of degradable $D O C$ in landfill waste $(\mathrm{Gg})=W \times M C F \times D O C \times D O C F$

$W=$ Amount of landfill waste $(\mathrm{Gg})$

$M C F=$ Methane correction factor

$D O C=$ Ratio of degradable organic carbon

$D O C F=$ Ratio of adaptable by bio organism in $D O$

$\mathrm{DDOCma}_{T}=$ Amount of $D D O C \mathrm{~m}$ accumulated in landfill until $T(\mathrm{Gg})$

$\mathrm{DDOCma}_{T-1}=$ Amount of $\mathrm{DDOCm}$ accumulated in landfill until $T-1$ year $(\mathrm{Gg})$,

$\mathrm{DDOCmd}_{T}=$ Amount of landfill in $T$ year $(\mathrm{Gg})$

DDOCmdecomp $_{T}=$ Amount of $D D O C m$ degraded in $T$ year $(\mathrm{Gg})$

$k=$ Rate constant of methane generation

$\mathrm{CH}_{4}$ generated $_{T}=$ Amount of methane generated in $T$ year(Gg)

$F=$ Volumetric ratio of methane in landfill gas

$R=$ Recovery ratio

$O X=$ Ratio of oxidation ratio

The values of $D O C$ and $M C F$ can be found in Table II and Table III [5]. And theanother method is direct calculation which e using the monitoring concentration of landfill gas emissions. Following equation was adopted to calculate the emission of greenhouse gases.

$$
\mathrm{CH}_{4} \text { generated }=Q \times 16 / 22.4 \times C \times 24 \times 365 \times(1-R)
$$

where

$Q=$ Volumetric Flow rate $\left(\mathrm{Sm}^{3} / \mathrm{hr}\right)$

$C=$ Concentraion of methane $\left(\mathrm{kg}-\mathrm{mol} / \mathrm{Sm}^{3}\right)$

From 2003 to 2004 year the emission of methane gas increased rapidly but, after the year 2005 the rate of increase became small. But, theresults of calculating the equation (5) was quite different as shown in the Fig. 1. The overall tendency was the increase of the methane gas emission, but in terms of more detailed period it could be seen that the characteristics of landfill region's internal phenomena [3], [4].

TABLE II: THE VALUES OF DOC AND DOC

\begin{tabular}{|l|l|l|}
\hline Component & $\mathrm{DOC}(\%)$ & $\mathrm{DOC}_{\mathrm{F}}(\%)$ \\
\hline Rubber/Leather & 58.42 & 11.5 \\
\hline Etc & 22.97 & 43.2 \\
\hline Wood & 35.96 & 32.4 \\
\hline Fibrous & 45.61 & 38.2 \\
\hline Sludge & 15.77 & 12.2 \\
\hline Food & 26.64 & 51.9 \\
\hline Paper & 40.55 & 55.7 \\
\hline
\end{tabular}

TABLE III: THE VALUES OF MCF IN LANDFILL

\begin{tabular}{|l|l|}
\hline TYPES OF LANDFILL & MCF \\
\hline sanitary landfill - unaerobic & 1.0 \\
\hline sanitary landfill - semi-aerobic & 0.5 \\
\hline non-sanitary landfill - heoght $>5 \mathrm{~m}$ & 0.8 \\
\hline non-sanitary landfill - heoght $<5 \mathrm{~m}$ & 0.4 \\
\hline unclassob landfill & 0.6 \\
\hline
\end{tabular}

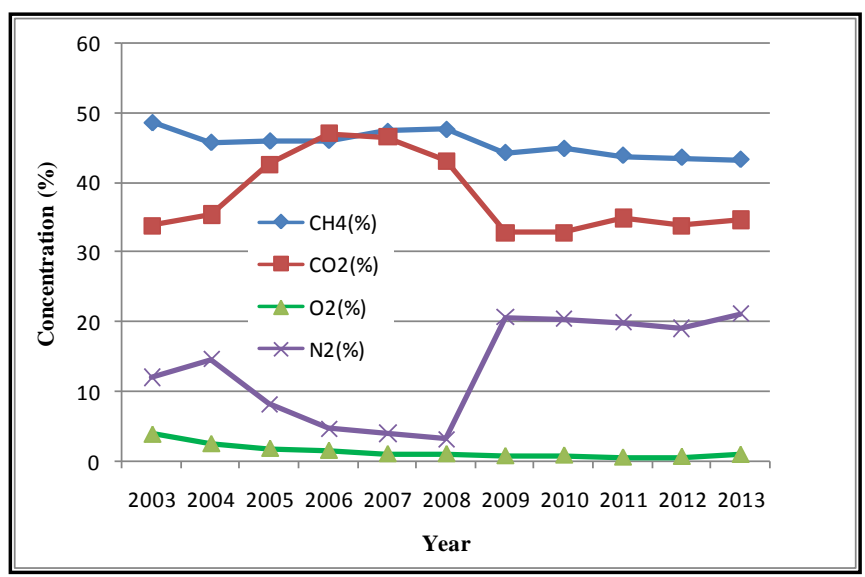

Fig. 2. Concentration of landfill gas emission.

The generation of landfill gas is classified to four steps which can be expressed as the aerobic process initially to final unaerobic process. After one or two years from landfill, the amount of methane and carbon dioxide gas becomes nearly constant. The generation time of greenhouse gas is estimated as from five to twenty years [6]. 
We think that these phenomena are expressed as the direct monitoring data of methane gas emission, but IPCC methods cannot explain these detailed tendencies completely. And our landfills are divided into two regions, the first region was closed in 2000 due to the full capacity of given landfill capacity. And the second region was opened after the first region has been closed, and are managed nowadays. Another famous method of greenhouse emission is that of Scholl Canyon \& EPA. These results are shown in the following Fig. 3 [2], [3]. These are the unit of $\mathrm{m}^{3} /$ minthat is volumetric flow rate of gas emission. And Fig. 2 shown above is the landfill gas emissions in the unit of concentrationas methane, carbon dioxide, oxygen and nitrogen [3].

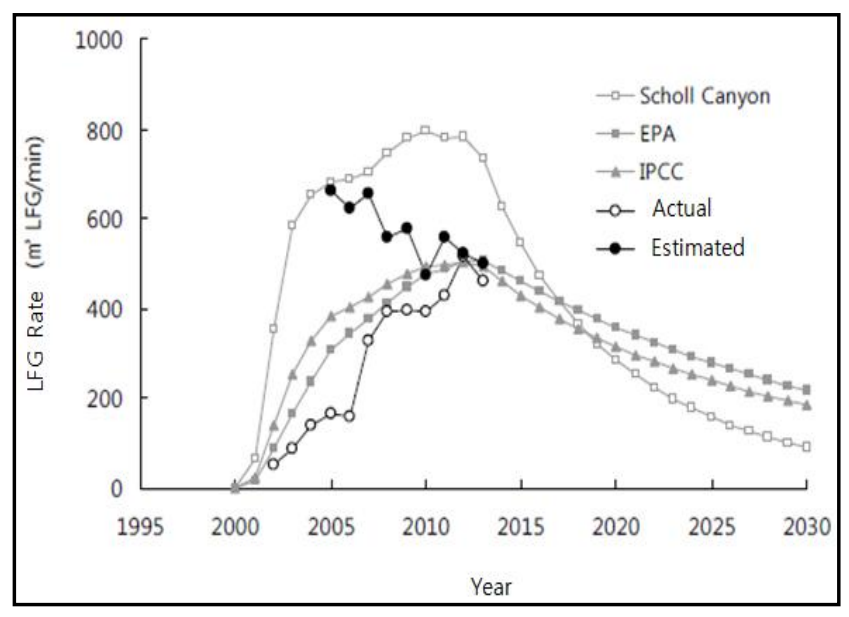

Fig. 3. Comparison methods of gas emission.

As descraibed above, two regions has different tendency of landfill gas generation, therefore different managing technologies should be adopted to optimal control [7].

The concentration of landfill gas components is different from each other. Methane shows nearly constant until the year of 2008, then decreased gradually until recent time in Fig. 2. But carbon dioxide showed rapid increase and decrease during 2003 to 2009, which was maximum in 2006, then had minimal value until recent year. Nitreogen had a little complicated tendency as shown in the figure, and oxygen showed gradual decrease until ten years.

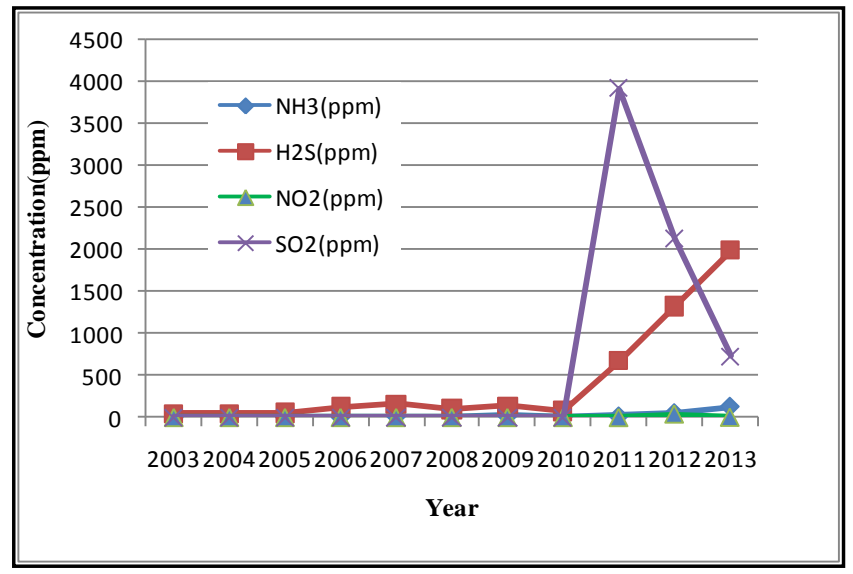

Fig. 4. Tendency of major air pollution gases.

The gas emission flow rate estimated by several methods are almost similar in terms of tendency with maximum values in the year of 2005 to 2010. Scholl Canyon method shows large difference between 2002 to 2015, but other methods are very similar with IPCC, EPA. Therefore it would be accurate to estimate the volumetric rate of landfill gas by any methods which are suggested in this study. If third landfill site would be used, the composition would be different.To estimate accurately, continuous monitoring of affecting factors must be proceeded in landfill wastes characteristics during every year [8].

Fig. 4 is the other odor generating \&air pollutant in the landfill gasas explained earlier [3].

As shown in Fig. 4, three components are nearly constant until 2010, but sulfur dioxide gas increased abruptly in 2011 and then decrease. Hydrogen sulfide gas has almost nearly increased until recent period.

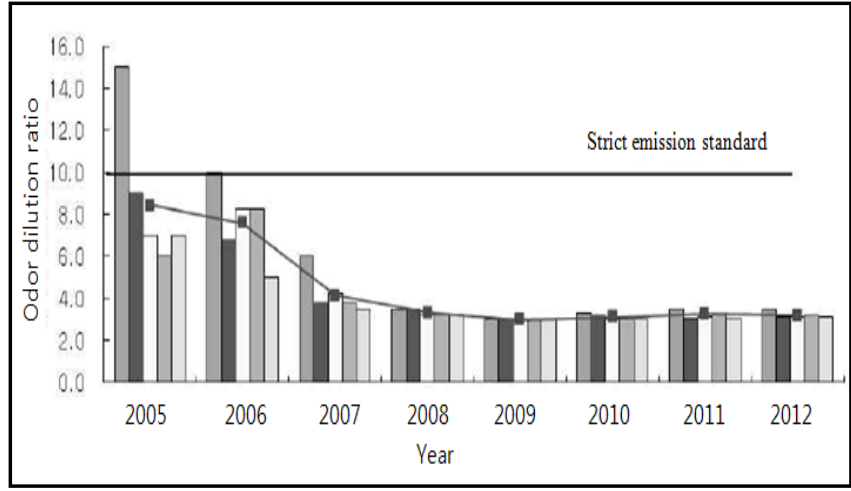

Fig. 5. The odor dilutiion ratio neighboringlandfill sites.

Fig. 5 shows the odor concentration of landfill site boundary in recenteight years [2]. As shown in the figure, odor concentration becomes small gradually and after the year 2009 all the points are almost the same in lower values of odor concentrations. This trend continues until now,andis due to the methane gas reutilization system with odorous compoenents incineration.

The optimal treatment of wastes is very important and unavoidable problem to be solved for the pleasant life of all human-being. Landfill site is therefore very indispensable utility for treatment of many kinds of waste disposal.

Many studies have been conducted for the landfill site [9], [10] and in our study, all kinds of landfill gas components were investigated and estimated qualitatively during recent years. Especially greenhouse gas within landfill gas emission was studied to decrease the direct emission into the atmosphere. And the odor components were analyzed to make less civil appeals about the unpleasants smells and air quality. It could be found that the landfill siate can be the significant recycling facility to lessen global warming in the near future.

\section{CONCLUSION}

A comprehensive analysis of landfill gas component was investigated with the classification of general pollutant gas and greenhouse gas. The detailed estimation of major gases were compared, and more effective management method of landfill utility was investigated with odor components management.

\section{REFERENCES}

[1] G. Tchobanoglous et al., Integrated Solid Waste Management: Engineering Principles and Management, Mcgraw-Hill, 1993. 
[2] Post Environmental Impact Assement of Landfill Site, Sudokwon Landfill Site Management Corp., p. 325, 2012.

[3] Post Environmental Impact Assement of LandfillSite, Sudokwon Landfill Site Management Corp., p. 329, 2013.

[4] Analysis of Landfill Gas Generation and ON-Site Monitoring in Sudokwon Landfill Site 2013, Sudokwon Landfill Site Management Corp., pp. 68-83, 2014.

[5] IPCC Guidelines for National Greenhouse Gas Inventories, IPCC, vol. 5, pp. 3.8-3.10, 2006.

[6] C. J. Park, "On the making resources of methane gas \&odor characteristics in landfill sites," J. of Korean Society of Odor Research and Engineering, vol. 11, pp. 203-208, 2012.

[7] S. W. Jung, "Estimation of VOCs Emissions from LandfillSites in Korea," J. of Korean Society for Atmospheric Environment, vol. 2, pp. 209-222, 2006

[8] Recycling of LFG with CDM, Sudokwon Landfill Site Management Corp., pp. 40-48, 2007.

[9] Y. S. Koo et al., "A review of the estimation methodology of methane emission in a landfill using inverse modeling technique," J. of Korean Society of Odor Research and Engineering, vol. 12, pp. 111-123, 2013

[10] S. Y. Lee, et al., "Effect of ammonia on the oxidation of methane by methanotrophs," J. of Korean Society of Odor Research and Engineering, vol. 11, pp. 41-46, 2012.

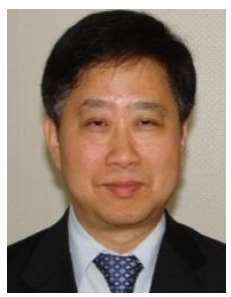

University).
Park Chan Jin graduated from Korea University, and got his master and $\mathrm{PhD}$ degrees in the same university. His major fields of research are the air pollution control, greenhouse gas technology and odor management technology. His other interest is green growth policy. He is now a full-professor in Incheon National University at Urban and Environmental Engineering School. He is a member of INU ensemble taking part in piano (chamber orchestra of his 